\title{
Translating English-Arabic Business-to-Consumer Advertisements: a Domesticating Approach
}

\author{
Ahmad Mustafa Halimah $^{1}$ \& Zainab R Aljaroudi ${ }^{2}$ \\ ${ }^{1}$ Associate Professor of Applied Linguistics and Translation Studies, Department of English Language, College of \\ Arts, King Faisal University, Saudi Arabia \\ ${ }^{2}$ Lecturer at the English Language Unit, Arab Open University, Dammam Branch, Saudi Arabia \\ Correspondence: Ahmad Mustafa Halimah, Associate Professor of Applied Linguistics and Translation Studies, \\ Department of English Language, College of Arts, King Faisal University, Saudi Arabia.
}

Received: July 4, 2019

doi:10.5430/wjel.v9n2p42
Accepted: July 18, 2019 Online Published: July 26, 2019

URL: https://doi.org/10.5430/wjel.v9n2p42

\begin{abstract}
This study investigates the linguistic and cultural problems encountered in translating English-Arabic Business-to-Consumer (B2C) Advertisements in a Saudi environment, using a domesticating approach to assess the quality of the translated advertisements. Baker's taxonomy (2011) of equivalence analysis and Halimah's (2015) translation quality assessment 'ACNCS' criteria will be used for the analysis and discussion of seven B2C advertisements randomly chosen mainly from brochures. Results of the discussion and analysis of the examples used in this paper have indicated that there is an urgent need for domesticating and culturalising the translation of advertisements as they tend to lose essential linguistic and cultural aspects of the original texts and cause textual violations in the B2C Arabic advertisements. Some suggestions and recommendations have been made to help translators adjust their translation methods to fit the Arabic linguistic and cultural contexts as well as those who are interested in carrying out further research in this field.
\end{abstract}

Keywords: translation of B2C advertisements, domesticating, foreignising, culturalising, linguistic

\section{Introduction}

Due to the growing international exchanges in the field of commerce and the strong relationship between globalization and translation, the need for translation of advertising has increased recently (Guidère, 2001; Shiyab, 2010). Translating advertisements is considered to be one of the most difficult types of translation because it is not enough to only transfer semantic meanings and achieve equivalence between the source and target languages but it is also crucial to carry through the persuasive functional equivalences from the SL to TL (Veronika, 2013; Brierley, 2005).

Generally, the majority of English-Arabic B2C advertising and promotional material tends to be poorly translated. This could be due to the inappropriate use of translation strategies normally used in a foreignising approach such as transliteration, literal translation, borrowing, which affect the linguistic and cultural meanings of B2C advertisements (Newmark, 1988; Polio, 1997; Wang, 2012: Guerra, 2012). This, in turn, may affect the influence of the B2C advertisements on the Target Language (TL) readers (Ahmed, 2015).

In 1972, Hurbin noted in his article cited in Smith (2002: 21) that "Studies into the translation of the advertising message are still relatively rare or sketchy". This could also ring true to English-Arabic advertisement translation in general and to B2C advertisements in particular. Therefore, the main objective of this study is twofold: to identify the linguistic and cultural mistranslations and ambiguities of $\mathrm{B} 2 \mathrm{C}$ advertisements occurring as a result of the inappropriate use of translation strategies such as transliteration, literal translation and borrowing, strategies often employed in a foreigninsing approach, on one hand; and; on the other hand to demonstrate how to overcome linguistic and cultural translation problems at word and above word levels and find linguistically and culturally acceptable equivalences of translation at the grammatical, textual and pragmatic levels. Achieving such objectives would then help us introduce a domesticating approach that would be the most appropriate to use in translating English-Arabic B2C advertisements and could also then be enlisted by translators to help them overcome such problems and difficulties in similar contexts (Venuti, 1993). 


\section{Theoretical Considerations}

More recently, there has been a growing interest in the translation of promotional material and advertising texts (Ho, 2004; Torresi, 2010). Advertising in general and B2C advertising in particular are used here to refer to the commercial relationship in business, i.e. between marketers and individual consumers, that involves two interactive processes: communication and persuasion and is also considered "an integral part of modern culture" (Guidère, 2001; Ulvydiene, 2013; Torresi, 2010; Leiss, etal, 1986 as cited by Alagha, 2006:16). This triad combination of communication, persuasion and culture in a single English advertisement seems to make its translation into a language like Arabic quite difficult and challenging. The reason for such difficulty could be attributed to the linguistic, discoursal and cultural differences between the SL and TL.

The relationship between translation and culture has been addressed from different perspectives over time. Newmark (1988: 94) perceived culture as "a way of life" while De Mooij (2004: 181) described it as "the glue that binds groups together". Venuti (1995/2008: 36) defined translation as "the forcible replacement of the linguistic and cultural differences of the foreign text with a text that will be intelligible to the target-language reader" and Schaffner, 1998 as cited in Jabir (2006: 37), defined it as "a process of intercultural communication whose end product is a text which has the ability to function appropriately in specific situations and context of use". Nida and Taber (1982:199) however, viewed intercultural translation as "a translation in which the content of the message is changed to conform to the receptor culture in some way, and/or in which information is introduced which is not linguistically implicit in the original".

Guidere (2006:2) looked at the translation of international advertising material as a campaign to adapt the company's ad's message "to the specificities of the local environment of the hosting countries targeted by the campaign", using French ads translated into Arabic. He seemed to overemphasize the significance of the semiotic and graphic aspects of the ad in translation, overlooking ,in the example of "the lady perfume Tuscany" he used, that localizing the graphic image of the lady could potentially backfire rather than be accepted in a social and cultural context like that of Saudi Arabia, for instance. Guidere foreignised the translation of the ad where he could have made it less graphic and more textual by simply domesticating it at word, textual and pragmatic levels. Furthermore, this example consolidates the belief that localization and domestication are not alike when they are used as translation methods.

Fadee \& Hashemian (2015) conducted a 'comparative study of English-Persian verbal metaphors using Black's (1962) interaction theory of metaphor to analyze the translation of the English commercial: LG breakfast set is wife! into Persian. They confirmed the importance of "culture, image and music" as influential factors in the translation of verbal metaphors in TV advertising and yet although they used a mix of methods and procedures (localization, domestication, adaptation, addition and reduction) in their analysis of the data, they claimed that the translation of the aforementioned English ad was not appropriate because it had 'gender limitation' in a conservative society like that of Iran.

Another random mix of translation strategies was proposed by Fan (2017:2) for English -Chinese translation of commercial advertising. Fan claimed that "the purpose of commercial advertising translation is to effectively communicate and realize the purchase action... and for achieving this ideal purpose, the following translation strategies can be used as a reference" (literal translation, free translation, creative translation, adaptation translation and idioms translation). Again, the translator seems to prioritize the translation of the economic dimension of the ads and overlooks the fact that the target readers would first check the validity of the ad according to their cultural norms and perception before noticing the purchasing element implied in the ad. That is why choosing an appropriate method along with the right procedures/strategies is essential for solving not only linguistic/cultural problems in ad translation but also meeting the expectation of the economic/material purpose of the ad in the first place.

George Ho's article (2004:222) "Translating advertisements across Heterogeneous Cultures" is rather interesting as it tackles the problem of ad translation from different perspectives. For him, translating ads is not merely a transfer of language and culture but also a transfer of the psychology of the source ad reader's mindset to that of the target ad reader with all the spiritual feelings and free aspirations associated with it. Furthermore, he successfully linked the value of translation with all its operations involving language, culture and the value chain of commodity production in his proposed 'value-driven theory of ad translation'. However, this could be a tall order very few translators could successfully put through because of culture specific constraints, be they economic, religious, political or a combination of all three, as in the case of the Gulf States setting in general and Saudi Arabia's in particular.

How good or poor the quality of B2C advertisement translations are depends largely on the fulfillment of their "purposes in a specific situation or discourses" (Schaffner, 1997: 2; Vermeer, 2000:229). In other words, translating foreign advertisements according to the consumer`s background is considered as a necessity in order to eliminate Published by Sciedu Press 
cultural and ideological differences between both the source and target languages (Ghobadi \& Rahimian, 2015). How to solve translation problems in general and $\mathrm{B} 2 \mathrm{C}$ advertisement translation in particular such as transliteration, literal translation, borrowing, (Newmark, 1981; Nord, 1997/2014:29) and to achieve successful intercultural communication between participants belonging to different cultures, was explored in his influential book "the Translator's Invisibility", where Lawrence Venuti (1995/2008) developed the theory of valorizing the foreign described by Friedrich Schleiermacher in 1813 into two systematic translation approaches namely: foreignization and domestication which provide a linguistic and cultural guidance to a translator during the translation process. In other words, the former tends to be content-orientation/SL emphasis approach whereas the latter tends to be addressee-orientation/ TL emphasis approach which as explained below will be used as a yard stick for assessing the quality of English/Arabic B2C Advertisement translation in this paper.

According to Venuti (1993: 36), 'foreignization' is defined as an "ethnodeviant pressure on those values to register the linguistic and cultural differences of the foreign text, sending the reader abroad". It allows the reader to be exposed to the foreign culture of the source text as it preserves the foreignness of that culture in the target text. Venuti (ibid: 37) also noted that "foreignising translation signifies the difference of the foreign text, yet only by disrupting the cultural codes that prevail in the target language".

The role of a translator in a foreignising approach is visible. They seem to keep foreign linguistic features and cultural associations in the target text in order to introduce the target language readers to the foreign cultural and linguistic systems. The strategies that tend to enhance this approach are 'transliteration, literal translation and borrowing' which this paper argues against the use of when translating English B2C ads into Arabic as they would validate not only the TL linguistic rules but also the Target cultural norms and expectations of the TL readers.

To minimize the loss of essential linguistic, cultural and even commercial aspects of the original advertisements and in order not to cause any textual violations in the B2C Arabic advertisements, Venuti's (1993:36) domestication approach will be adopted throughout this study. He defined domestication as an "ethnocentric reduction of the foreign text to target-language cultural values, bringing the author back home". In other words, a domesticating approach places priority on target-language fluency which aims to avoid the foreignness of the target text and adaption of culture-bound items in order to be linguistically and culturally accepted by target language readers. Venuti, (2000:362) described the process of domesticating a foreign text as follows: "the foreign text is rewritten in domestic dialects and discourses, registers and styles, and this results in the production of textual effects that signify only in the history of the domestic language and culture. The translator may produce these effects to communicate the foreign text, trying to invent domestic analogues for foreign forms and themes". Domestication could be described as the replacement of the foreign terms, concepts, items, stylistic features, etc... in a way to meet the target linguistic and cultural systems as an attempt to make the target text acceptable and comprehensible to the target language readers.

Venuti, (1995/2008:1) described the features of a domesticated target text as "a translated text, whether prose or poetry, fiction or nonfiction, is judged acceptable by most publishers, reviewers, and readers when it reads fluently, when the absence of any linguistic or stylistic peculiarities makes it seem transparent, giving the appearance that it reflects the foreign writer's personality or intention or the essential meaning of the foreign text - the appearance, in other words, that the translation is not in fact a translation, but the "original"". One of the most important features of a domesticating approach is 'fluency and naturalness'. That is, the translator expresses his thoughts, ideologies, feelings, etc. freely in order to reproduce a transparent self-representation version of the source text.

Venuti, (1995/2008:1-2) described the role of a translator in a domesticating approach as invisible "the more fluent the translation, the more invisible the translator, and, presumably, the more visible the writer or meaning of the foreign text". He, (2000:359) posted that "the translator negotiates the linguistic and cultural differences of the foreign text by reducing them and supplying another set of differences, basically domestic, drawn from the receiving language and culture to enable the foreign to be received there". Thus, the translator should find solutions to deal with the linguistic and cultural differences of the foreign text and work in a way to naturalize the target text by being a transparent figure during the translation process.

\section{Research Question}

The following question was formed to investigate the problems and difficulties in translating English- Arabic B2C advertisements:

Does using inappropriate translation strategies produce linguistically inaccurate and culturally inappropriate translated advertisements? If it does, what are the issues caused and how can they be addressed? 


\section{Methodology}

The aim of this study was to investigate the linguistic and cultural inaccuracies of translated English-Arabic B2C advertisements in a Saudi setting and make an attempt to suggest a domesticating approach to address such issues.

To achieve this aim, a set of 15 English-Arabic B2C advertisements was chosen randomly for the study. Due to a lack of space, and for the sake of convenience, only 7 samples were selected mainly from freely available brochures from several sources: 2 from Lulu Hypermarket Mall, 1 brochure from Avon Beauty, 1 from Hyper Panda Supermarket, 1 from E-Max Electronic Shop, 1 from Jarir Bookstore, and 1 from Alwaseela Ads Weekly Newspaper. All names and any other information likely to identify the translators were removed. The value of the data used in this study has a special significance because the companies that used these advertisements are the most popular markets for consumers living in the Eastern province of Saudi Arabia where the majority of the consumers are Arabic-speaking residents. Furthermore, the advertisements are written in both English and Arabic which as separate languages tend to carry different linguistic denotations and cultural connotations to each other as explained below.

Throughout this study, it has been assumed that the majority of consumers receiving these B2C advertisements are Arabic speaking consumers living in a Saudi environment. Therefore, it is expected that the major function of the Arabic translations of these advertisements should fulfill "the target audience's mind to high mental level" (Valdes, 2008:42) and meet target readers` linguistically and culturally oriented expectations.

To see how and why the translators of these translated English-Arabic B2C advertisements, made linguistic and cultural inaccuracies in a Saudi context and failed to use appropriate procedures and/or strategies, Baker`s taxonomy (2011), which provides a systematic approach in analyzing the textual message at different levels i.e. the word, above word, grammatical, textual and pragmatic levels, will be used along with Halimah's criteria (2015) of "accuracy, clarity, naturalness, communication and stylistic features" to assess the quality of the translated texts. (See Appendixes A and B for more details on Baker's taxonomy and Halimah's Criteria respectively).

To ensure the validity and reliability of these instruments, a pilot study was carried out and its results were found to support the expected results of the current study. The pilot study consisted of three procedures: B2C advertisements data collection, administration and analysis. This procedure consisted of $6 \mathrm{~B} 2 \mathrm{C}$ advertisements which were taken mainly from Lulu hypermarket, E-max and Avon brochures from March 2016 to March 2017. These B2C advertisements were analyzed according to Baker`s taxonomy (2011) in order to find out any ambiguities and mistranslations which could complicate the meaning or be inappropriate in accordance with the linguistic and cultural systems of the target language i.e. Arabic. They were then evaluated according to Halimah`s criteria (2015) for assessing the quality of creativity in translation.

The study instruments were feasible and reliable because the data analysis supported the expected results. Findings showed that translators used inappropriate translation strategies: transliteration, borrowing and literal translation which negatively affected the quality and accuracy of the target message and, consequently, the target message.

It is not the purpose of this study to show that translators of English Arabic B2C advertisements tend to commit serious linguistic inaccuracies in their translations but rather that these translators seem to lack the proper Arabic linguistic and cultural background needed and use inappropriate foreignising strategies such as 'transliteration, literalness and borrowing' in their translations.

\section{Data Analysis and Discussion}

Nida and Taber (1982:163) stated that "once the process of reconstructing has been completed, the next essential step is the testing of the translation. This should cover the entire range of possible problems: accuracy of rendering, intelligibility, stylistic equivalence". In other words, as part of data analysis and assessment of the quality of the translation of the B2C advertisement samples used in this study, and due to lack of space and as a matter of convenience, only seven examples of the B2C advertisements are given and discussed using Baker`s taxonomy (2011) and Halimah`s criteria (2015). 
Published in a brochure for Lulu hypermarket in March 2016, the following advertisement: "Tender Coconut Ice Cream" was translated into Arabic as "آيس كريم جوز الهند تندار". The translator seems to have enlisted 'transliteration' as a foreignising translation strategy which aims at printing the word of the source language with the closest corresponding letters of the target language alphabets. It is normally used to keep foreign linguistic features and cultural associations in the target text so in this example instead of translating the word 'Tender' to an acceptable equivalence in the target language, they transliterated it as 'تتدار', using Arabic corresponding letters.

It seems that the translated Arabic advertisement is linguistically inaccurate and culturally inappropriate because it violates accuracy at textual and pragmatic levels. The use of transliteration adds an element of vagueness to the advertisement as it seems to complicate the meaning by adding the word "تندار" that doesn `t belong to the linguistic system of the Arabic language and has no meaning in the Arabic language and/or culture, hence, makes it difficult for Arabic language readers to understand. Furthermore, the word negatively affects the cohesion of the advertisement as it fails to function as an adjective describing "coconut ice cream" and target language readers would not be able to visualize the image of being tender and understand why the translator used such a foreign word in this context. Moreover, the word 'Tender' when describing food refers to something smooth and not tough; therefore, the use of transliteration as a translation strategy in this advertisement enlarges the gap between both the source and the target languages and is used unnecessarily because there is an acceptable equivalence to the adjective in the target language.

Against Halimah`s criteria (2015), the translation of the advertisement doesn't achieve criteria no. 1 and 2 "accuracy and clarity" as it was translated inaccurately so instead of providing an accurate and clear meaning to the target language readers, the word 'تندار' makes the statement more vague and difficult to understand. The advertisement also fails to achieve criterion no. 4 "communication", where the translator is expected to transfer the emotional effect along with the accurate meaning, because the vagueness of the advertisement didn't allow the transfer of the emotional effect in the source text to the target text, hence, the advertisement can't be read as naturally as it can in the original context.

The translator should be able to provide an alternative to the word 'tender' with a word that belongs to the linguistic system of the target language in order to be acceptable at both linguistic and cultural levels and make the آيس" " advertisement easy for target language readers to understand. An example of an appropriate translation would be Smooth Coconut Ice cream" which is more acceptable to the target language and its readers because it's linguistically accurate and culturally appropriate.

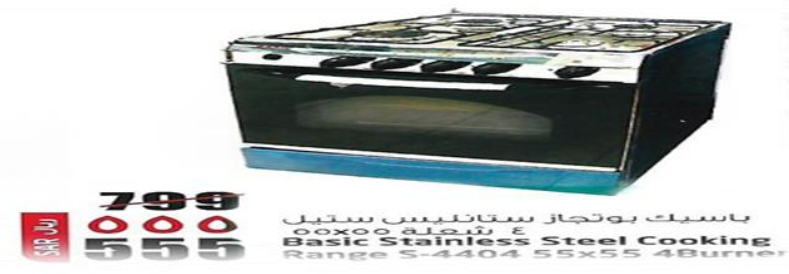

Figure 2. " Basic Stainless Steel Cooking ... 4 Burner"

Published in a brochure for Lulu hypermarket in March 2017, the following advertisement: "Basic stainless steel cooking ... 4 Burner" was translated into Arabic as "باسيك بوتجاز ستانليس ستيل ... The translator looks to have used three translation strategies: transliteration, literal translation and localization. Unlike transliteration, literal translation refers to translating word-for-word rather than transferring the overall meaning of the source text. Localization as a strategy refers to using a word that is normally used by a particular group of people in a particular region. The translator unsuccessfully transliterated "basic" into "باسيك" and "stainless steel" into "ستانليس ستيل"; as well as literally translated "4 burner" into Arabic " 4 " 4 ". Furthermore, they wrongly localized the translation of the word "cooking” by translating it into "بوتج".

According to Baker`s taxonomy (2011), the target advertisement is not accurate at word, grammatical, textual and pragmatic levels. In the current advertisement, the translator transliterated "basic" and "stainless steel" into "باسيك", and "ستانليس ستيل", which are considered to be foreign words not belonging to the linguistic system of the target language i.e. Arabic, despite the words already having equivalents in the target language. By transliterating them, the accurate pronunciation of the vowels are lost in translation because Arabic doesn 't have equivalent 'sounds' for /a/ in 
"basic" and /er/ in "stain". Another issue is "بوتجاز" which as a local word used in Egypt, not in Saudi Arabia, may not be understood by the target language readers. The translator should have translated the source advertisement using standard Arabic in order for the target advertisement to be clear and understood by the target language readers.

Furthermore, an element of oddness is added to the target advertisement because of the literal translation of " 4 burner" into "شعلة 4 ". The construction of the sentence is made inaccurate grammatically due to the lack of correspondence between the number "4" and word "شعلة". Numbers that are more than 1 need to have plural nouns in the Arabic language and so, hence, the translator should have translated the phrase as "شعلة 4" "شعلات " instead of."

The target advertisement sounds awkward because of the inappropriate use of these translation strategies. The use of transliteration and localization as well as insufficient attention to grammatical mistakes often produces a target text that is incoherent and unacceptable at both linguistic and cultural levels. The target language readers may not understand the target advertisement because it doesn't make sense to them. Thus, the translator has not achieved the accurate meaning and the overall idea expressed in the source advertisement.

According to Halimah`s criteria (2015), the translation of the advertisement doesn't achieve criterion No. 1 "accuracy" because of its use of transliterated words that don't belong to the linguistic and cultural systems of the target language. Moreover, the use of literal translation caused unsuitability of number which, as a result, affected the cohesion of the target advertisement negatively. Criterion No. 2 "clarity" wasn't achieved because of the transliteration of the content words of the target advertisement, which makes it unclear and difficult to be understood by TL readers, and neither were criteria Nos. 3 and 4 "naturalness and communication". The translator didn't portray the accurate/specific meaning of the source advertisement as well as its overall meaning. Therefore, no emotional effect was transferred and as a result, the target advertisement doesn 't appear as it does in its original context.

The translator could have produced an alternative translation that is understandable, acceptable and more effective

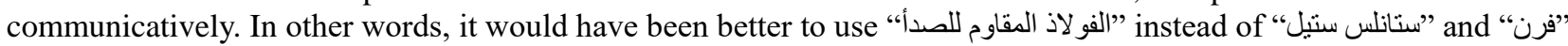
instead of "بوتجاز". A translation such as " فرن بقاعدة فو لاذية مقاومة للصدأ تحتوي على 4 شعلات / an oven with a steel base that's rust-resistant and contains 4 burners" would have been more acceptable and appropriate to the target language and target language readers i.e. linguistically accurate and culturally appropriate to Arabic-speaking people living in Saudi Arabia.

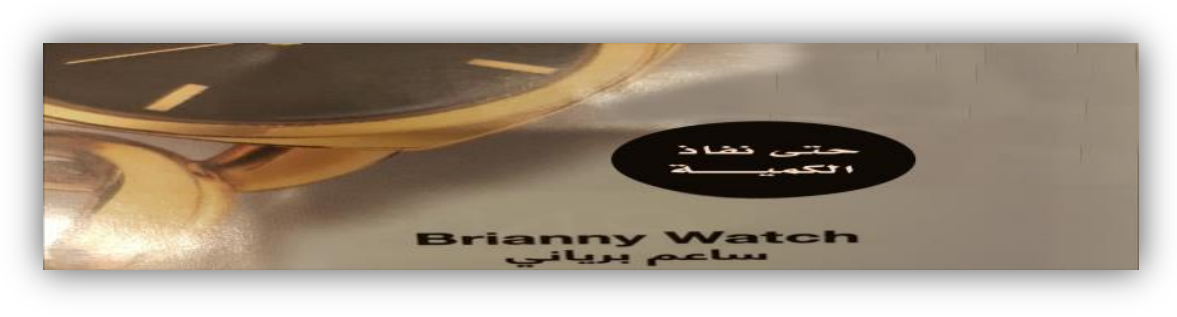

Figure 3. "Brianny Watch"

Published in a brochure for Avon Beauty for a Purpose from 20 January to 17 February 2017, the following advertisement: "Brianny watch" was translated into Arabic as "برياني ساعم". The translator looks to have enlisted two translation strategies: transliteration and literal translation. The target advertisement is not linguistically accurate and culturally appropriate because the translator didn`t pay careful attention to the spelling mistake in the word " "ساعم", which should have been written as "ساعم" " The wrong spelling of a target word such as target advertisement read and sound vague and be difficult for TL readers to understand. Moreover, they have transliterated a target word, "Brianny", into "برياني" which represents a type of food made of rice and meat in the Saudi culture although the source advertisement doesn't mention anything related to food or meals. Thus, transliterating "Brianny" in Arabic as "برياني" would make TL readers expect food and, therefore, they wouldn't be able to understand the intended idea of the target advertisement. The target Arabic advertisement does not achieve accuracy at the textual and pragmatic levels because there is no cohesion and so due to this lack of cohesion and coherence TL readers would have no idea whether the translator means a kind of rice or not. Even if the translator meant a kind of rice, it would not be comprehensible because not only is the target word "ساعم misspelled but it also doesn't belong to the linguistic system of Arabic and so has no linguistic meaning. Hence, the overall message implied in the target advertisement is vague and incomprehensible to the Arabic language readers. 
According to Halimah`s criteria (2015), the target translation doesn't achieve criterion No. 1 "accuracy" at both the linguistic and cultural levels, because the word "برياني doesn't suit the context of the current advertisement as it should have expressed a kind of watch. Moreover, the translator didn`t pay attention to the spelling mistake in the word " and so violated criterion No. 2 "clarity" affecting the ability of the target language readers to understand it let alone to appreciate it. As for criteria No's, 3, 4 and 5 "naturalness", "communication" and "style", the translator didn't use the accurate linguistic devices of the target language to describe the object in question which as a result failed in reflecting the intended meaning and emotional aspects of the source advertisement which plays an important role in attracting the target consumers for purchasing the object in question. Therefore, the target advertisement cannot be read as it is in the original context.

The translator could have produced an alternative translation that is understandable, acceptable and more effective communicatively. In other words, it would have been better to use the word "ساعم" and to clarify what is meant by "برياني" instead of leaving it to the target language reader to guess. The target advertisement seems to have needed a modifier in order to become more understandable to the target language readers. A translation such as " ساعة من ماركة براي ني / Watch of BrianNey Make" is more acceptable and appropriate to the target language and target language readers i.e. linguistically accurate and culturally appropriate to Arabic speaking people living in Saudi Arabia.

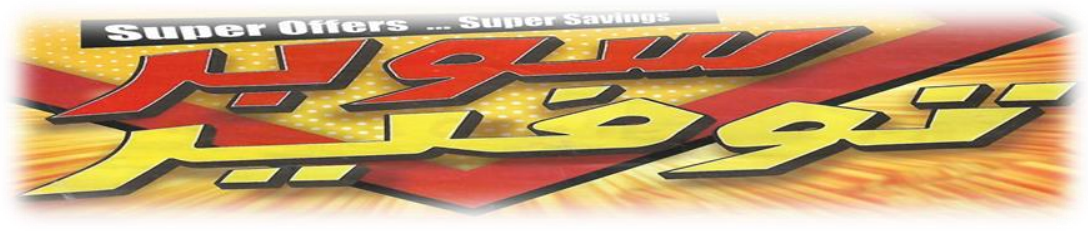

Figure 4. "Super Savings... Super Offers"

Published in a brochure for HyperPanda Market in January 2017, the following advertisement: "Super savings... Super offers" was translated into Arabic as "سوبر توفير". Using transliteration as a translation strategy did not help the translator in achieving the target linguistic and cultural accuracy. On the contrary, it seems to have added an element of vagueness to the advertisement because it complicated its meaning by adding the word " which doesn't belong to the linguistic system of the TL and has no meaning in the TL and/or culture. This, therefore, makes the advertisement difficult for Arabic language readers to understand and negatively affects its cohesion because the translator didn't achieve textual and pragmatic accuracy. The use of "سوبر", a foreign word meaning excellent, doesn't express the intended meaning in the Arabic language and was unneeded because Arabic has a lot of equivalent words expressing excellence and good quality. Furthermore, there is an important difference between /p/ and $/ \mathrm{b} /$ in pronunciation and yet in the target language there is no differentiation between these two sounds. All in all, although the translator used a common foreign word, the Arabic language readers may not know the exact meaning of "سوبر" which could affect the quality of the target text as well as its intended meaning.

With regard to Halimah`s criteria (2015), the translation of the target advertisement has not achieved the following criteria: criterion No. 1 "accuracy" the translation of the target advertisement is not accurate due to the use of a foreign word which doesn 't belong to the linguistic system of the Arabic language; criterion No. 2 "clarity" the use of a word which doesn't belong to the linguistic system of the target language affects the clarity of the target advertisement. As a consequence of inaccuracy and lack of clarity, the linguistic and cultural systems are negatively affected. On one hand, the target advertisement is inaccurate linguistically at both word and textual levels; the word "سوبر" is not an Arabic word, therefore, it seems to affect the cohesion of the target advertisement. And, on the other hand, the target advertisement is culturally inappropriate because the word " affects the pragmatic level of the advertisement by providing unclear meaning to the target language readers. With respect to criteria No. 3, 4 and 5 "naturalness, communication and style", as a result of not having used the target linguistic devices, the stylistic features and the emotional effects were not reflected in the target advertisement and,therefore, it cannot be read as it is read in the original context.

Instead of deleting the second half of the source advertisement, the translator could have translated it adding a few Arabic words to make it sound and read better. An alternative translation would be such as " في عروضنا الأقوى... وفّر للحد الأقصىى/in our best offers... you make the most savings" which is linguistically accurate and culturally appropriate. Furthermore, it is attractive to the target consumers and also easy to remember because the words used are common 
words in Arabic advertising language and the Arabic parallel structure rhyme and sound rhythmic.

THINK LAPTOPS. THINK EMAX.

THINK LAPTOPS. THINK EMAX.

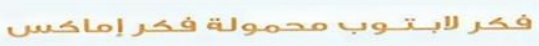

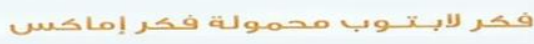

Figure 5. "Think Laptops. Think Emax"

Published in a brochure for E-max Store in September 2016, the following advertisement: "Think laptops. Think Emax" was translated into Arabic as "فكر لابنوب محمولة. فكر إيماك". According to Baker's taxonomy (2011), the target Arabic advertisement doesn't achieve linguistic and cultural accuracy due to the use of literal translation as a translation strategy.

The use of literal translation strategy makes the translation read odd because the forms and norms of the target language aren't followed. In other words, the form of the target advertisement didn't achieve the target linguistic and cultural systems because the translator failed to achieve equivalence at grammatical, textual and pragmatic levels. Furthermore, the target advertisement is incohesive where the translator linked words in an illogical way that doesn't suit the linguistic system of the target language. They also neglected the acceptable organization of words within a sentence with regard to suitability of gender. In other words, nouns should be described by adjectives that suit them in gender, person, tense, number and aspect. For example, the noun "لابنوب" can`t be described by the feminine word " "محمولة" is masculine. Along with this, the translator also used borrowing as a strategy to transfer the word "لابتوب": a well-known borrowed word from English. As it is still a foreign word and has an equivalent in the target language, it could be replaced by the Arabic equivalent "حانسوب" in a way of domesticating it.

Although the translator has provided a part of the idea expressed in the source text, the translation of the target advertisement doesn't achieve all Halimah's criteria (2015). With regard to criterion No. 1 "accuracy", for example, the advertisement is inaccurate grammatically as far as gender is concerned. It also didn't achieve textual and pragmatic accuracy; the form of the advertisement is inaccurate which makes the text incohesive and causes it to become unclear and unacceptable linguistically and culturally. According to criterion No. 3 "naturalness", the translator failed to use the norms and forms of the linguistic system of the target language as well as the right word order. As for criterion No. 4, "communication", the translator neglected the role of the emotional effect of the original text. As the original advertisement only used content words, the translator has to clarify the idea in a better manner so that the target advertisement would reflect the emotional effect of the original advertisement and sound as an original. Criterion no. 5 "style" wasn't achieved either because the translator didn't enlist the linguistic devices of the TL in order to reproduce the advertisement in an acceptable and attractive manner to Arabic language readers.

Even though the source advertisement consists of only content words to express its message, the translator should be able to render the whole idea to the target language using prepositions in order for the target text to be linked in a cohesive way and be linguistically and culturally acceptable in the TL. Translations such as: " هل تفكر بامتلاك حاسوب عندما تفكر بامتلاك حاسوب محمول، "Are you thinking of buying a laptop? Then, think of Emax" or " عحمول؟ إذن فكر بايماكس (فكر بايماكس / When you think of buying a laptop, think of Emax" are more appropriate and acceptable at both the linguistic and cultural levels of the target language because they are domesticated.

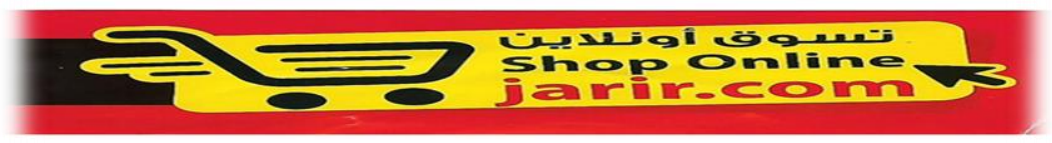

Figure 6. "Shop Online"

Published in a brochure for Jarir Bookstore from February to March 2017, the following advertisement: "Shop online" was translated into Arabic as "تسوق أوناين". Using transliteration as a translation strategy has made the Arabic 
advertisement lose its target linguistic and cultural accuracy as it is not well-known to the TL readers. Textual and pragmatic equivalences have not been achieved because of lack of cohesion and coherence in the Arabic structure of the advertisement. This created an incomprehensible advert which Arabic consumers would be reluctant to accept and /or react to positively because of its incompatibility with the Arabic consumers' linguistic norms and cultural expectations.

According to Halimah`s criteria (2015), the translation of the target advertisement doesn't achieve criterion No. 1 "accuracy" because of its use of transliteration rather than a linguistically and culturally suitable equivalence in the target language. Criterion No. 2 "clarity" has not been achieved either because Arabic speaking consumers would find the advert unclear due to its lack of cohesion and coherence. As a result of Criteria 1 and 2 not being achieved, Criteria no. 3, 4 and 5 "naturalness", "communication" and "style" haven't because the forms and norms of the target language, as well as the target linguistic devices, were not followed in order to reproduce the target advertisement in an accurate and a cohesive way. This has made the Arabic advertisement void of any communicative effect and meaningless.

It is worth mentioning that using the borrowed word "الإنترنت" would be more appropriate both linguistically and culturally because it is widely used by the target language readers and more popular than the word "أونائن". Therefore, this alternative translation: "تسوق عبر الإنترنت Shop via the Internet" is more acceptable and appropriate and sounds less foreign to the TL and TL readers.

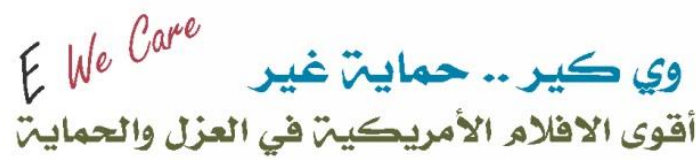

Figure 7. We Care

Published in a brochure for Alwaseela Ads Weekly Newspaper on 24 December 2016, the following advertisement: "We care" was translated into Arabic as "وي كير ... حماية غير". Using transliteration as a translation strategy seems to have violated accuracy in the Target advertisement at the word, textual and pragmatic levels. Adding a second part "وي كير", just to make a rhyme makes an odd and confusing phrase for the TL reader because the first part doesn't belong to the target linguistic and/or cultural system. Thus, as a result, meaning is lost and communicative purpose and effect ultimately made nonexistent because of a lack in cohesion and coherence at both textual and pragmatic levels.

According to Halimah's criteria (2015), the translation of the advertisement doesn't achieve criterion no. 1 "accuracy" because it uses transliterated words that don 't belong to the linguistic and cultural systems of the target language and, moreover, unnecessarily adds the phrase "حماية غير. This makes the Target Text fail criterion No. 2 "clarity" as transliterating the whole advertisement makes it unclear and difficult for the target language readers to understand. The target advertisement also doesn't achieve criteria No. 3 and No. 4 "naturalness and communication" respectively. The translator failed to produce the accurate meaning of the source advertisement as well as its overall meaning. Therefore, no emotional effect was transferred and as a result, the target advertisement doesn't appear as it is in the original context.

Instead of transliterating the whole advertisement, the translator could have used understandable and appropriate equivalences from the target language and been more creative in their translation. An alternative translation would be "you are the center of our attention", where domestication makes the advertisement linguistically accurate and culturally appropriate as well as catch the attention of Arabic speaking consumers.

\section{Conclusion}

Based on the brief analysis and discussion mentioned above, we can conclude that translating English-Arabic B2C Advertisements in a Saudi environment tends to give rise to linguistic and cultural problems at word, textual and pragmatic levels. Most of the linguistic and cultural inaccuracies of the examples used in this study are due to the use of inappropriate translation strategies such as: transliteration, literal translation, borrowing. Globally, these strategies represent a foreignising approach to translation which "signifies the difference of the foreign text, yet only by disrupting the cultural codes that prevail in the target language" (Venuti, 1995/2008:20). That is why the foreignising strategies used in the above examples are not appropriate for use in the translation of English -Arabic 
B2C advertisements for consumers in the Kingdom of Saudi Arabia.

As the most used strategy in this study (see table below), transliteration causes several problems with regard to the comprehension of the target language readers as well as the creation of some violation at word, textual and the pragmatic levels. When an English-Arabic translator uses transliteration, he/she makes it more complex for the target language readers to comprehend the intended idea of the target $\mathrm{B} 2 \mathrm{C}$ advertisement because some English concepts may not be known and/or familiar to them. Furthermore, the transliterated items may not have corresponding comprehensible meaning in the target language and/or culture as they may not be part of the linguistic and cultural systems of the target market.

Table 1. Foreignising strategies used in the current study (except localization)

\begin{tabular}{ccccc}
\hline Strategy & Transliteration & $\begin{array}{c}\text { Literal } \\
\text { Translation }\end{array}$ & Borrowing & Localization \\
\hline No. of Times Used & 7 out of 7 & 3 out of 7 & 1out of 7 & 1 out of 7 \\
\hline
\end{tabular}

More specifically, the inaccuracies examined above could be categorized into the following types:

a) Wrong choices of lexical items often cause cultural inappropriateness as well as linguistic inaccuracies. Translators tend to choose inappropriate or unacceptable lexical items during the translation process as a result of the following:

- Limited knowledge of the target language and/or culture.

- Lack of knowledge of the subject matter.

- Concentration on persuading the target consumers at the expense of providing accurate meanings. In other words, translators exaggerate the benefits of the product or service being advertised in order to persuade the target consumers while ignoring to transfer accurate meaning into the target language.

b) Violation of cohesion and coherence devices. Failing to apply the natural forms and norms of the target language leads to the production of target texts that sound odd and awkward to the target language readers.

c) Typographical errors often result from lack of attention and/or lack of proofreading during the typing process.

In addition to the solutions and alternative translations suggested at the end of each example given above, the translator of English-Arabic B2C advertisement could also consider the following:

a) A domesticating approach to translating English-Arabic B2C advertisements where translators emphasize the target language and target culture at word, textual, pragmatic, cultural and creative levels. The main purpose of domesticating the translation of the above B2C advertisements was to evoke in the TL reader the same emotional impacts the SL reader receives from the original text.

b) Translation agencies should provide their employed translators with intensive translation courses in order to help them develop linguistic and cultural awareness as well as translational competences of their own.

c) Translators have to familiarize themselves with the subject matter and the discourse of the material being translated.

d) Translators have to exert mental effort to determine the most appropriate translation strategies to use in order to reproduce creative translations.

e) Translators are ought to be conversant with specialized dictionaries in order to consider all available equivalents before deciding on the most accurate, clear, natural and communicatively effective ones.

Due to the limited scope of this study, researchers who are interested in carrying out further research in this field could investigate the translation issues and problems of other advertising areas business-to-business advertisements and could also apply the domesticating approach to investigating the translation of other promotional issues and materials.

Since the area of B2C advertisements has not been well researched, translation researchers could expand this study as follows:

a) Increase the size of the corpus of this study and concentrate on a specific type of category of advertisements such as website, newspapers, television...etc. in order to make definite conclusions.

b) Examine B2C advertisements which are translated from languages other than English and/into Arabic. 
c) Make a comparative survey study of the reception and reaction of B2C advertisements between the source and target consumers.

d) Investigate translation agencies and their requirements for hiring translators.

\section{References}

Alagha, B. (2006). The Translation of Fast-Food Advertising Texts from English to Arabic. University of South Africa.

Baker, M. (2011). In other Words: A Coursebook on Translation. London and New York: Routledge. https://doi.org/10.4324/9780203832929

Brierley, S. (2005). The Advertising Handbook. London and New York: Routledge.

De Mooij, M. (2004). Translating Advertising, in B. \&. Adab, the Translator: Key Debates in the Translation of Advertising Material, 179- 198). Manchester: St. Jerome Publishing. https://doi.org/10.1080/13556509.2004.10799176

Fan, H. (2017). Strategies for Translation of English Commercial Advertisement from Intercultural perspective. Open Journal of Social Sciences, 5, 38-45. https://doi.org/10.4236/jss.2017.511004

Fadee, S., \& Hashemian, M. (2015). On the Translation of Advertisements: A Comparative Study of English-Persian Verbal Metaphors, Journal of Language Teaching and Research, 6(1), 225-229. Academy Publication. https://doi.org/10.17507/jltr.0601.28

Ghobadi, M., \& Rahimian, P. (2015). Cultural Filters in Rendering Advertisements: A Case Study of Iran. Translation Journal.

Guerra, A. F. (2012). Translating Culture: Problems, Strategies and Practical Realities. A Journal of Literature, Culture and Literary Translation, 1-27.

Guidère, M. (2001). Translation Practices in International Advertising. Translation Journal.

Guidere, M. (2006). The Translation of Advertisements: from Adaptation to Localization. Translation Directory.

Halimah, A. M. (2015). “Teaching Translation of Poetry: A Collaborative Approach”, Journal of_English Language \& Literature Studies, 5(1), 26-36, February 2015. https://doi.org/10.5539/ells.v5n1p26

Halimah, A. M. (2017). English-Arabic-English Creative Translation: A Practical Course, International Islamic Publication House, Riyadh, Saudi Arabia.

Ho, G. (2004). Translating Advertisements across Heterogynous Cultures. In B. \&. Adab, The Translator: Key Debates in the Translation of Advertising Material, Special Issue, 221-243. New Zealand: Routledge. https://doi.org/10.1080/13556509.2004.10799178

Jabir, J. (2006). Skopos Theory: Basic Principles and Deficiencies. Journal of the College of Art.

Newmark, P. (1981). Approaches to Translation. UK: Pergamon Press.

Newmark, P. (1988). A Textbook of Translation. UK: Prentice Hall International (UK) Ltd.

Nida \& Taber. (1982). The Theory and Practice of Translation. Netherlands: United Bible Societies.

Nord, C. (1997/ 2014). Translating as a Purposeful Activity: Functionalist Approaches Explained. London and New York: Routledge. https://doi.org/10.4324/9781315760506

Polio, C. (1997). Measures of Linguistic Accuracy in Second Language Writing Research. Language Learning, 101-143. https://doi.org/10.1111/0023-8333.31997003

Schäffner, C. (1997). From Good to Functionally Appropriate: Assessing Translation Quality. Current Issues in Language \& Society, 1-5.

Shiyab, S. M. (2010). Globalization and its Impact on Translation. In S. M. Shiyab, Globalization and Aspects of Translation, 1-10. UK: Cambridge Scholars Publishing.

Smith, K. (2002). The Translation of Advertising Texts: A Study of English-Language Printed Advertisements and their Translations in Russian. University of Sheffield.

Torresi, I. (2010). Translating Promotional and Advertising Texts. London and New York: Routledge.

Ulvydiene, L. (2013). Psychology of Translation in Cross-Cultural Interaction. 3rd World Conference on Psychology, Counselling and Guidance, 1889-1898. Lithuania: Procedia - Social and Behavioral Sciences. 
https://doi.org/10.1016/j.sbspro.2013.07.054

Valdés, R. M. C. (2008). Creativity in Advertising Translation. Universidad de Oviedo, 37-56.

Venuti, L. (1993). Translation as cultural Politics Regimes of Domestication in English, in T. Hawkes, Textual

Practice, 35-47. London and New York: Routledge. https://doi.org/10.1080/09502369308582166

Venuti, L. (1995/2008). The Translator`s Invisibility. London and New York: Routledge. https://doi.org/10.4324/9780203360064

Venuti, L. (2000). Translation, Community, Utopia, in L, Venuti, the Translation Studies Readers, 359-362. London and New York: Routledge. https://doi.org/10.4324/9780203446621

Vermeer, H. J. (2000). Skopos and Commission in Translational Action, in L. Venuti, the Translation Studies Readers, (2000:221-232). London and New York: Routledge.

Veronika, B. (2013). How to Translate Advertisement and Marketing Texts. Proz.

Wang, F. (2012). An Approach to the Translation of Brand Names. Academy Publication, 1945-1949. https://doi.org/10.4304/tpls.2.9.1945-1949

أحمد, م. أ. (2015). اللغة العربية في الإعلام بين الواقع والمأمول. مكتبة الألوكة

\section{Appendix (A): Baker`s taxonomy (2011)}

Baker`s analytical framework (2011) is a very useful and structured model based on finding textual equivalence of both source and target texts at all levels; starting from the smallest unit of language i.e. word level, and moving to examining the text within a pragmatic context. It is a useful approach to analyze such equivalence at several different levels; at word level, above word level and at grammatical, textual and pragmatic levels.

At word level, the analysis concentrates on morphemes, which are "the minimal formal element of meaning in language", words, "the smallest unit of language that can be used by itself" and the lexical meaning of a text which can be described as "the specific value in a particular linguistic system" (Baker 2011: 9- 11). In an advertising context, it is well-known that words are not used arbitrarily. Instead, they are chosen with much care in order to generate the curiosity and interest of the target consumers which in turn assists in attracting and persuading them to purchase. It is sometimes quite difficult to determine an equivalent for a linguistic item of the target text. The decision is based on several factors; the choice of the translator depends on the target language system, expectations of the target language readers and cultural appropriateness. Translators should make appropriate translations that meet the expectations of the target language readers as otherwise their translations may appear either ridiculous or inappropriate. Therefore, they have to convey the overall meaning instead of translating a text word by word bearing in mind that there is no one-to-one word correspondence between languages because what can be represented by a single word in one language could be represented by two or three words in another. For example, an advertisement launched in a brochure of Carrefour in March 2017, "buy in bulk and save" was translated into "كثرّ ووفقرّ twhere words were used in Arabic.

Equivalence above word level deals with collocations "certain words to co-occur regularly in a given language" idioms, which can be described as a stretch of language with a different meaning when occur together and fixed expressions (Baker 2011: 52). These linguistic features are embedded in one`s culture and considered to be a challenging area in translation. Some collocations are frequently used in a particular field or discipline and may appear odd in another while others have a certain meaning when seen individually and a completely different meaning when seen with other words. With respect to idioms, they are sometimes hard to recognize and understand and yet in some cases, they are easily found because they express untrue conditions or because of their ungrammatical form. They are not easily translated because they may have a literal meaning and an idiomatic one have a similar counterpart in the target language with regard to the surface but they reveal different meanings. In other words, Collocations are flexible i.e. can occur in many forms. However, idioms and fixed expressions are less flexible.

Grammatical equivalence is related to the grammar of a particular language and can be expressed in two dimensions: morphologically; the set of words in a language and expressed in terms of gender, number, person, tense aspect and syntax; the way these sets of words are organized in a language and expressed in terms of verb, noun, adjective and adverb. Baker (2011: 92) described grammar as "the set of rules which determine the way in which units such as words and phrases can be combined in a language and the kind of information which has to be made regularly explicit in utterances". In translation, grammatical choices are obligatory and unlikely to change as they do so over a long period of time whereas lexical choices are optional and are more likely to change. 
Textual equivalence ensures that a text is both coherent and cohesive to the target language readers through the way it is organized and the amount of known and new information provided. The translator has to reproduce a text with information organized in a logical sequence in order for it to be meaningful to the target language readers. Cultural restrictions should be taken into account in order for a text to be pragmatically accurate and culturally appropriate for the target language readers.

\section{Appendix (B) Halimah's (2015) The Five Criteria Model for evaluating translated advertisements.}

Bassnett, (2014 cited in Halimah, 2015:27) pointed out that "there is no universal canon according to which texts may be assessed". Therefore, the criteria proposed by Halimah (2015) and explained in more detail in Halimah (2017) are suitable and useful to assess the creative translation. They include 'accuracy, clarity, naturalness, communication and style features'.

The seven examples of English/Arabic Ad translations are to be graded on five-point scale areas. This represents the range of approximate equivalence with the highest degree of 'adequacy and validity' from being a poor translation to being a highly skilled ad translation. In order of importance, they are as follows:

1. Accuracy is the most important criterion to assess the quality of a translated text. To be accurate is to represent something in accordance with the way it actually is. It refers to the conveyance of the exact and precise meanings of the source text to the target text. To be certain about achieving 'accuracy' in translation, the following questions could be asked: Has the translator been faithful in rendering the exact meanings of the ST to the TT? Has any information mentioned in the ST been missed or omitted? Has any new information been added to the TT? Is there any shade of meaning missing? Has the overall meaning of the ST been transferred successfully to the TT? etc.

2. Clarity in translation is an integral part of the comprehension process of the TT reader. To be clear is to be intelligible without causing the TT reader to exert extra mental effort to understand the content of the TT. In other words, clarity in translation means that the reader can understand the text without any difficulty or having the need to refer to any off-site explanation whether inside the text or in a form of footnote. To be certain about achieving 'clarity' in your translation, the following questions could be asked: Is the TT easy to understand? Does it require from the target reader any extra exerted effort to comprehend it? Does it read smoothly and comfortably? Has the ST Message been communicated clearly to the reader of the TT? etc.

3. Naturalness in translation refers to the ability of the creative translator to apply appropriate natural forms and norms of the Target Language to the source text, which he /she is translating; be these forms and norms linguistic, sociolinguistic, psychological, sociocultural, communicative or other. To achieve naturalness in your translation the following questions should be asked: Does the TT sound and read like an authentic English text? Does it have the dynamicness and idiomaticness normally used in an authentic English text? Does it have the 'natural wow factor?' etc.

4. Communication in translation in general and in creative translation particularly involves transferring not only the meaning but also the emotional aspects of the ST to the TT readers as effectively and faithfully as they are communicated to the ST readers in the first place. In other words, a creative translator has to ensure that they understand the communicative purpose of the ST and endeavour to achieve it in the TT, be it poetry, novels, short stories, drama, oratory or any other type of literary text. The following questions should be asked to check for this criterion: What is the main communicative purpose of the ST? For example, is it to persuade, to entertain, to delight, to instruct or to inform? Does the TT carry the same meaning and emotional force of the ST?

5. Style in literary texts refers to the linguistic choices the author makes in his/her writing to tell a narrative, to describe events, objects and characters or to voice out his/her ideas and views in a manner of his /her choosing, be it formal, informal, casual or archaic. The author's style in literary texts tends to influence how we interpret the facts and information. Therefore, a creative translator need to be aware of these features and be able to transfer the stylistic features of the ST to the TT with the same stylistic force used by the ST writer or speaker. In other words, you need to identify the historical, geographical, and cultural dimensions of the style used in ST and endeavour to apply it to the TT with utmost accuracy, clarity, naturalness and communicative force. 